\title{
Erratum to: Ergativity and the complexity of extraction: a view from Mayan
}

\author{
Lauren Eby Clemens · Jessica Coon • Pedro Mateo Pedro • \\ Adam Milton Morgan • Maria Polinsky • Gabrielle Tandet • Matthew Wagers
}

Published online: 26 November 2014

(C) Springer Science+Business Media Dordrecht 2014

\section{Erratum to: Nat Lang Linguist Theory \\ DOI 10.1007/s11049-014-9260-x}

Due to an unfortunate turn of events this article was published with two erroneous values in the text related to Figure 2. Erroneous values W6 and W7 at the end of the accompanying paragraph that should read W4 and W5. Please find on the following page Figure 2 repeated with the correct paragraph that should be regarded by the reader as the final version.

The online version of the original article can be found under doi:10.1007/s11049-014-9260-x.

L.E. Clemens · P. Mateo Pedro · M. Polinsky $(\bowtie) \cdot$ G. Tandet

Harvard University, Cambridge, MA, USA

e-mail: polinsky@fas.harvard.edu

J. Coon

McGill University, Montreal, Canada

A.M. Morgan · M. Wagers

University of California at Santa Cruz, Santa Cruz, CA, USA 


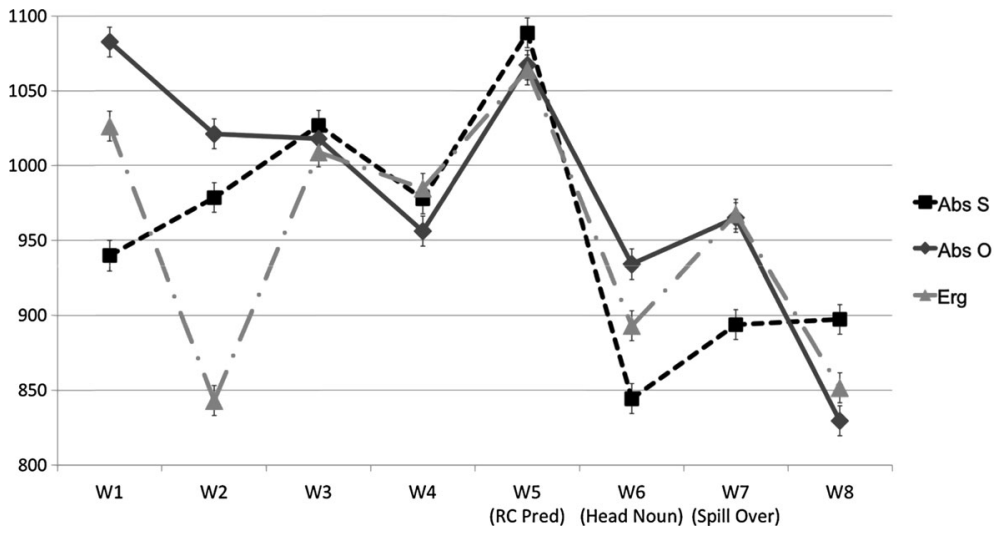

Fig. 2 Reading time $(\mathrm{ms})$ for transitive and intransitive relative clauses in Avar (adapted from Polinsky et al. 2012)

Figure 2 shows the reading time data from that self-paced reading experiment. The authors found that participants read the heads of relative clauses with absolutive subject gaps faster than those with either ergative subject gaps or absolutive object gaps. This difference is particularly reflected at words 6 and 7 below. Note, however, that there was no difference between ergative subject gap conditions and absolutive object gap conditions at W4 and W5. 